\title{
Teaching of writing in two rural multigrade classes in the Western Cape
}

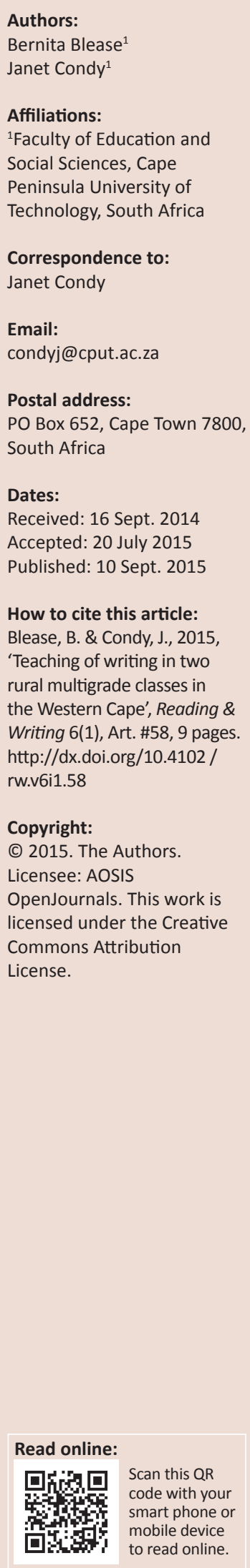

The purpose of this research project was to understand how Cambourne's theory of social constructivism, particularly his four instructional principles, was applied to the teaching of writing in two rural multigrade Foundation Phase classrooms in the Western Cape. Multigrade schools account for $30 \%$ of all primary schools in South Africa, but in most cases teachers are not able to provide quality education to learners. Writing in rural multigrade Foundation Phase schools is a largely neglected area for teacher development and research. Even those teaching multigrade classes are not sure how to approach it. The national curriculum, as well as our South African constitution, encourages teachers to inspire children with values based on respect, democracy, equality, human dignity and social justice. However, the two rural multigrade classes in this research project faced many challenges that hindered their ability to reach these goals. The main theoretical framework underpinning this study was based on Cambourne's social constructivist theory, particularly his instructional principles including explicit, systematic, mindful and contextual teaching principles. This research was a qualitative study embedded within an interpretive case study. Two Foundation Phase teachers working in multigrade classrooms were purposively selected for this research. In conclusion, there is evidence that these two teachers used some of Cambourne's instructional principles, in varying degrees, when teaching writing in their multigrade classes.

\section{Introduction}

To improve social cohesiveness of all South Africans in a non-discriminating society, the South African Manifesto on Values, Education and Democracy (South Africa, Department of Education 2001a) was drafted. This document and the White Paper 6 (South Africa, Department of Education 2001b) sketch democratic values for youthful South Africans in the learning environment to eradicate oppression and social injustices. From both these documents, social justice, equity, and equality emerge as three of the most important values that teachers, learners, and families strive to realise. Johnston (2010:20) states that we live in a multi-cultural society with laws that promise equal rights to all: the right to be as free as possible of biases based on ethnic group, gender, nationality, religion, socio-economic condition, sexual orientation, or disability.

Although multigrade schools account for approximately $30 \%$ of all primary schools in South Africa, many multigrade rural children do not receive equal access to quality education (Bloch 2009, 2010; Taylor 2008). The reality is that many South Africans living in poverty, which is widespread, are vulnerable, powerless, and isolated (Pretorius \& Mampuru 2007; Prinsloo 2005). Multigrade teaching is often established as a result of necessity; often the result of political or educational rationalisation (Brunswic \& Valerien 2004), population density resulting from ruralurban migration, excessive numbers of learners in certain grades, and competition for schools that are seen by parents as being more desirable.

According to Potgieter (2010), they found that teachers in multigrade classes are neither qualified nor able to provide quality education to learners. It is particularly difficult to educate rural children: they come to school hungry despite the feeding schemes in many South African schools; lack of physical resources and learning materials as well as overcrowded classrooms further block the road to literacy.

Taylor (2008) states that, despite some criticism from the public, teachers are dedicated and work hard. Multigrade teachers face severe challenges and difficulties unlike monograde classrooms (Beukes 2006). They need to plan and prepare for more than one grade per lesson. In Namibia, Beukes (2006) shared the challenges multigrade schools face such as: little or no guidance for the teaching of combination grades, inconsistent learner attendance, teachers' lack of classroom management skills, mother-tongue influences, grouping, and time management. 
Hlalele (2012:269) attempts to define the concept 'rural' but states that the true meaning of the word eludes us due to its ambiguous connotations and the obvious comparison with 'urban' contexts. She suggests that rural dwellers work in agriculture, often for meagre rates of compensation, face barriers to learning, and operate in less than favourable policy environments. Czerniewicz and Brown (2014) concur with Hlalele by explaining that rural schools continue to experience poor learning conditions.

When endeavouring to describe 'multigrade' schools, Little (2007) highlights the most common terms such as combination class, composite class, mixed or multi-age teaching, and mixed-year or grade classes. Despite the many challenges found in multigrade classrooms, Little (2005:6) found that friendship patterns, self-concept, self-esteem, cognitive and social development were more favourable in multigrade schools. Therefore, a constructivist ethos is ideal in multigrade classrooms where teachers guide children, and children guide their peers towards their own independent learning and writing.

The aim of this research project was to contribute to the limited national information about writing practices in a South African rural multigrade context. The researcher attempted to understand how Cambourne's theory of social constructivism, particularly his four instructional principles, were applied to the teaching of writing in two rural multigrade Foundation Phase classrooms in the Western Cape.

\section{Theoretical framework}

This research was conducted in a rural area where poverty and illiteracy prevailed. To respond to this situation of socio-economic deprivation it was necessary to select an appropriate theoretical paradigm with great care. Hence, Cambourne's social constructivist theory was selected as applicable.

Cambourne (2004:26) defines social constructivism 'as a set of assumptions about learners and the learning process'. It is the process used to socially construct knowledge continuously. He states that learning to write should engage children in authentic, real and contextual writing activities that are inherently interesting and meaningful to the learner. Constructivism in a writing class, according to Cambourne (2004:26), juxtaposes four instructional principles as described in Table 1 below. In multi-grade classrooms, where writing knowledge and meaning are socially constructed,

TABLE 1: Four instructional principles of teaching and learning

\begin{tabular}{ll}
\hline Proposed dimension & Opposed dimension \\
\hline Explicit & Implicit \\
Systematic & Unsystematic \\
Mindful & Mindless \\
Contextualised & Decontextualised \\
\hline
\end{tabular}

Source: Cambourne, B., 2004, 'Holistic, integrated approaches to reading and language arts instruction: The constructivist framework of an instructional theory', in A.E. Farstrup \& S.J. Samuels (eds.), What research has to say about reading instruction, 3rd edn., p. 32, Th International Reading Association, Newark. strategies such as explicit, systematic, mindful and contextual teaching principles can be employed. He is aware of this oversimplification of a complex subject such as writing, but suggests this could create a platform from which to begin unpacking the multiple layers of meaning.

The explicit dimension refers to the practice of deliberately demonstrating and developing conscious awareness of visible writing processes, understandings, knowledge, and skills. Implicit teaching refers to the practice of deliberately leaving learners to discover and work out things for themselves (Cambourne 2004:32). Teaching systematically implies that teachers plan formally, logically, think ahead, and develop future lessons, activities, resources, and assessments that are needed and will be used. Unplanned instruction indicates little evidence of planning and is therefore unsystematic (Cambourne 2004:33). Mindful learning can be equated with metacognitive awareness: the state of being consciously aware of what is happening about you. According to Cambourne (2004:34), mindful learning is aligned with the discourse employed by teachers as opposed to 'mindless' teaching and learning. Teachers need to take account of children's interests when planning writing activities (Estyn 2011:13). They should provide numerous opportunities for children to be independent in their learning including writing skills. According to Cambourne (2004:37) contextualised learning makes sense to learners; it is uncomplicated and more likely to result in robust, transferable, useful and mindful learning. In contrast, decontextualised learning does not make sense to learners and leads to automatic, rigid, rote memorising. True learning is connected to the learner's environment. It is linked to what learners know about writing and their own personal experiences.

In order for learners to benefit from these constructivist instructional principles, Cambourne (2004:28) suggests that learners need to engage with the teaching and learning process. Engagement includes a variety of distinctive behaviours; learning can take place only if the learners are convinced that they are capable of learning or doing what is being demonstrated, that there is a purpose or value in the learning, learners are free from anxiety, and if they admire, respect, like or have hope in the teaching and learning writing process.

\section{Writing}

This study portrayed writing as a means of communication to gain or share understanding by using print, to contribute ideas, to apply knowledge and skills, as well as to record important information (Blease 2014). Although complex, writing remains the most common form of communication and requires knowledgeable others to help develop these skills. For most rural multigrade teachers and learners, writing is a process and an opportunity to learn to become independent. Chetty (2010) posits that multigrade teaching can be used effectively to both foster independent, individualised learning, and ensure that marginalised learners regain their voice. Learners need to gain writing 
skills in order to break free from the stigma and stranglehold of poverty and illiteracy.

Three questions have guided the analysis of writing in rural multigrade Foundation Phase classrooms:

1. How do three authors describe and express what they mean by 'writing'?

2. How is 'writing' interpreted in the RNCS Foundation Phase document, which was the document in use at the time of data collection?

3. How is 'writing' taught in rural multigrade Foundation Phase classrooms?

How do three authors describe and express what they mean by 'writing'? According to the UNESCO (2004:13) report, literacy involves a continuum of learning in enabling individuals to achieve their goals, to develop their knowledge and potential, and to participate fully in their community and wider society. They further define 'writing' as the '... ability to identify, understand, interpret, create, communicate and compute, using printed and written materials associated with varying contexts.'

Similarly the NEEDU Report (2013) states that writing shapes the way we think, reason, and learn. The degree to which information is manipulated through writing dictates how well the information is integrated, learned, and retained. This report indicates that children in the Foundation Phase should be writing four times a week including one extended piece of writing. Their criterion for the development of writing skills per grade is highlighted as the following: Grade 1: writing sentences; Grade 2: paragraphs; Grade 3: extended passages.

Hamston and Resnick (2009:7) describe writing as a powerful way for people to develop an understanding of themselves and their world. Writing is a craft and an art. It requires people to have something to say and to say it well with words that capture the fine distinction of meaning. It is a concentrated act of making feeling, perceptions, and thinking visible, permanent, and important. Many writers believe that writing clarifies thinking.

How is 'writing' interpreted in the RNCS Foundation Phase document? At the time of data collection for this research project, the RNCS document (South Africa, Department of Education 2002) was the curriculum in practice; therefore it will be the RNCS curriculum that will be referred to in this paper. This curriculum only makes provision for monograde educators, which is the norm in South African schools. Although adjustments can be made to suit individual multigrade teachers, it leaves the teacher with a great deal of extra planning and lesson preparation, since separate lessons for each grade need to be arranged.

The RNCS document (South Africa, Department of Education 2002) offers content such as outlining writing skills and elements to be taught and acquired, and it provides teachers with practical examples of how to teach these skills and elements. The RNCS (South Africa, Department of Education 2002:2) Language Learning Area six Learning Outcomes (LO's) are listed according to a clear line of progression regarding language development, where skills are ranked in the following order: (1) Listening, (2) Speaking, (3) Reading and Viewing, (4) Writing, (5) Thinking and Reasoning, and (6) Language Structures. In this study, the discussion focuses on learning areas, LO (4) Writing, and LO (6) Languages.

The RNCS (LO 4), the Writing curriculum for Grades R to 3 is based on developmental theories. The curriculum develops and builds on skills from previous years and sets out more complex writing skills within each grade. Writing skills explained in the RNCS (South Africa, Department of Education 2002:11) include: handwriting skills; to be able to record learners' thoughts and ideas so that others can read them; writing conventions, such as spelling and punctuation, to make their writing understandable to others. Finally, learners discover that writing is a process that includes pre-writing, drafting, revising, editing, illustrating, and publishing. The LO 6 Language curriculum has been set out in accordance with the way Cambourne (2000) views learning language. Hsu (2009) highlights that we use speaking, reading and writing for different purposes, which entail different skills.

How is 'writing' taught in rural multigrade Foundation Phase classrooms? Teachers should teach and not assign writing (Scott et al. 2009:338). To write an essay children require demonstration, stimulation, and motivation. They should become self-directed and independent writers. They should be able to write in a way that is comprehensible and engages the reader in a desirable way. Children should be taught to re-think their writing. Davis and McGrail (2009:522) suggest that, by actively comparing and adjusting their writing according to readers' reaction, learners develop metacognitive skills of monitoring, diagnosing, revising, and editing. These skills are essential in improving the quality of writing (Dednam 2008).

Hamston and Resnick (2009:7) believe that writing is as valuable as reading. Writing is increasingly important for success in school and beyond where communicating effectively in writing is essential. They argue that children should write for pleasure and become effective writers, not only because they are expected to write. Writers develop several processes with practice rather than a single fixed process for writing.

Writing partners is a useful practice, particularly in a multigrade class (Hsu 2009). Children are paired in order to increase opportunities for student interaction. Student conferencing, critiquing each other's writing and recommending improvements are useful examples. Vygotsky (1986) reiterates that 'what the child can do in cooperation today, he can do alone tomorrow'. This allows the teacher to facilitate pairs of learners as opposed to being the only source 
of support. This in turn saves time and encourages learners to be independent. Hsu (2009) comments that mixed gender pairs work adequately, and considers strengths, challenges, organisational habits, personality, and learning support needs are involved with these activities.

In order to accommodate learners in rural multigrade settings, change is required. In order for change to be successful, elevated demands for teachers should be met (Johnston 2010:13), especially for teaching writing skills. These demands mean teachers have to:

- Develop considerable expertise.

- Plan systematic routines.

- Provide high quality instruction.

- Possess knowledge of writing skills.

- Plan strategies.

- Possess content knowledge.

- Be acquainted with assessment techniques.

- Acquire knowledge of remediation.

- Be able to know learners and their needs.

Teaching skills needed for writing should not be taught in isolation. Teachers should familiarise themselves with the curriculum and identify areas where they can integrate skills.

\section{Methodology}

The research was a qualitative study observing the writing methodology of two rural multigrade Foundation Phase teachers. Based on situational and contextual analysis (Henning, Van Rensburg \& Smit 2007:71), purposive sampling was selected in a non-random manner, based on member characteristics and specific criteria relevant to the research problem (Wiersma \& Jurs 2005:491). As a result of the literacy rates in rural multigrade schools, two Foundation Phase teachers working in multigrade classrooms were deliberately selected. The learners, per se, were not part of the study but their responses and work provided further indepth data to this qualitative study.

An important criterion was that the schools had to be multigrade schools or have a multigrade Foundation Phase class. The Northern District Education Office was approached to help identify schools that met these requirements. An additional criterion was identified by the Western Cape Education Department (WCED) officials. These two schools did not obtain good results in the WCED 2011 Systemic Results for Grades 3. Their literacy as well as numeracy levels were very low. Both schools were rural and had a multigrade class in Foundation Phase at the time of the study. The reason for this choice of school therefore depended heavily on convenience and low literacy levels.

Teacher A (50 years old) taught an Afrikaans Grade 2 and 3 multigrade class and was Afrikaans-speaking. In 2010, this class was visited once and observed four times over four weeks, from mid-July to end of August. The visits were on alternate Mondays. Data collection began at 08.30, and lasted until 10:00 for the four visits. This was the time period that the teacher used to teach writing.

In 2010, the teacher in the second school, who had been part of the sample, died during the early stages of the research. As a result of this, the principal and the WCED gave the researcher permission to begin data collection with another teacher from mid-July to the end of August 2011. Teacher B (23 years old), who was Afrikaans-speaking, became part of this research project in 2011. She taught Afrikaans to the Grade 2 and 3 multigrade class. The researcher paid one initial visit to the class at this school, and conducted four observations over four weeks from 08:30 until 10:00.

Henning et al. (2007) as well as McMillan and Schumacher (2006) encourage the use of data from a variety of sources. In 2011, within the boundaries of this qualitative case study, data was collected from a repertoire of observations, which were video recorded, and in-depth individual face-to-face interviews. English translations were made of the Afrikaans observations and interviews. Both Afrikaans transcripts and English translations were returned to the teachers to check the accuracy of translation. Correlations between each method of data collection were noted (Creswell 2012). Each interview and observation was transcribed exactly in order to understand how the data was to be collated, coded, and categorised (Creswell 2012). Transcripts were read and examined repeatedly to determine how these two teachers incorporated Cambourne's social constructivist instructional principles in their teaching and learning. All four of Cambourne's (2004:33) social constructivist teaching and learning instructional principles were employed to deductively analyse the data. These principles were: explicit, systematic, mindful and contextual teaching. These four principles have their diametric opposites and include: implicit, unsystematic, mindless and decontextualised teaching and learning. Cambourne (2004:33) explains that, although each of these dimensions is on a continuum, there may be at extremes of the field.

Written consent was obtained from the WCED for permission to conduct the study in both schools. A copy of this letter, as well as a letter requesting permission, was submitted to each principal and teacher and permission was granted by all. In order for Teacher A to be more comfortable, all communication and correspondence was conducted in Afrikaans. It was important to iterate that participants would remain anonymous, and where required pseudonyms were used, (Creswell 2012) thus maintaining confidentiality (Henning et al. 2007:73). The names of the participating schools and teachers were not disclosed in this study. Instead, they are referred to as Teacher A (TA) and Teacher B (TB) as well as School A and School B.

\section{Findings}

To answer the research question 'How has Cambourne's theory of social constructivism furthered the understanding of the teaching of writing in two rural multigrade classrooms 
in the Western Cape?' the researcher referred to Cambourne's four instructional principles and has provided evidence from teaching and learning episodes undertaken by both Teacher $\mathrm{A}$ and Teacher B.

\section{Explicit teaching versus implicit teaching}

Teacher A: The following extract from the observations shows how Teacher A used a poem to teach punctuation in preparation for a writing task.

TA: Let's look at this poem again.

What is at the end of line two?

L1: An exclamation mark.

TA: When do we use an exclamation mark?

WC: (There is silence).

TA: Will I use an exclamation mark when I ask a question?

L23: No.

TA: Why not?

L36: Because you use a question mark at the end of a question.

TA: So when will I use an exclamation mark?

WC: (Again there is silence).

TA: Will I use a question mark or an exclamation mark at the end of the following sentence? I said no!

L20: An exclamation mark.

TA: Yes, but why?

WC: (again there is silence).

TA: I use an exclamation mark to show expression or emotion. Why did the poet use an exclamation mark at the end of line 2 ?

L18: He is cross.

TA: Is the poet cross?

L18: No, I mean the person in the poem.

TA: Good.

Let's look at line 4.

What is at the end of line 4 ?

L13: A full stop because it's the end of a sentence.

This lesson was taught verbally through the medium of a poem. Teacher A did not explicitly demonstrate punctuation on the board, but she did verbally engage the learners by asking the meaning of using different punctuation marks, and why. In this way she was explicitly attempting to teach punctuation. When looking through the learners' exercise books, the researcher did not observe previous opportunities to engage with these skills. She concluded that in this case it may have been the first time that a lesson including question and exclamation marks was taught. A lack of deep engagement would negatively affect the way learners use exclamation marks and punctuation in the future (Cambourne 2004; Woolfolk, Hughes \& Walkup 2008). Implicit teaching was identified as the preferred method of teaching punctuation in this lesson.

Teacher B: Teacher B expected her learners to produce their own written work, but she was explicitly conscious of the writing skills they needed. During her interview the researcher asked Teacher B how she supported learners experiencing writing difficulties. Teacher B explained that time was spent developing and demonstrating various writing skills: spelling, sentence construction, and punctuation. She marked her books after school, listed errors, and pointed them out the following day as learning moments. The first twenty minutes of the next lesson were spent explaining and demonstrating these skills. At the start of every lesson that was observed she would begin by saying: 'Yesterday when I marked your books, I noticed ... so today we are quickly going to look at how we do ...'

The explicit method by which Teacher B taught writing skills to her learners was well received by her learners. During observations, when learners had to write news, the teacher demonstrated punctuation and sentence construction to her learners. After the demonstration, she gave learners the opportunity to apply, transform, and reflect on these skills. Her learners were engaged (Cambourne 2004; Woolfolk et al. 2008) in these activities. They began writing quickly; the majority of the learners completed their news writing within the allotted time. Grade 2 learners, however, struggled to begin or complete their writing tasks. It was noticed by the researcher that Grade 3 learners, who had completed their work, approached specific Grade 2 learners to assist them. Upon further investigation, it was again observed by the researcher that Grade 3 learners were scaffolding and mentoring Grade 2 learners and encouraging them to write their news. It was evident that there was already an element of social constructivism in place in Teacher B's class.

\section{Systematically planned teaching versus unsystematic, unplanned, unstructured teaching}

Teacher A: Teacher A had over 30 years of teaching experience in Foundation Phase, but did not wish to share her planning books or files. She did not volunteer to have them perused for research. She explicitly stated that every week, staff and grade teachers planned together but she was unwilling to share her planning with the researcher.

During one of the writing lessons observed, unproductive time was observed for 28 minutes before Teacher A began engaging learners in this particular activity. She wanted to hear the students' weekend news but implicitly and incidentally introduced other concepts such as 'months of the year', 'days of the week' and the 'weather'. After discussing these concepts, she asked them to tell her their news. She had not prepared them, however, to focus on a particular aspect of what had happened to them over the weekend. The duration of this lesson, in which the teacher sat on a chair and learners sat on a mat, was 1 hour 19 minutes. Learners had not yet begun to engage in a writing activity after all this time. This indicated that she had not systematically planned this particular writing lesson.

Teacher B: Despite Teacher B's lack of teaching experience, she willingly showed the researcher her weekly and daily 
planning. A line of progression of the development of the writing skills (word-building, vocabulary, sentence construction, and writing for different purposes) was easily identified. An example of this was presented in the learners' books where Teacher B used a word-building activity as the basis for a sentence construction lesson. Depending on how learners reacted on that day, she continued the following day either by reteaching word-building and vocabulary skills or extending their known knowledge. Personal extension notes were evident in her planning file and this was a clear indication of her systematic planning.

During the interview, Teacher B highlighted that she used word-building activities to assist learners develop a wider vocabulary. By increasing their vocabulary, she assisted her learners in constructing more complex sentences. Developing writing skills, word-building, vocabulary, and sentence construction (South Africa, Department of Education 2002) was made possible by experimenting with words they had learnt the previous day. From the learners' books it was evident that the continuation and consolidation of relevant writing skills were considered when learners wrote for different purposes.

\section{Mindful teaching versus mindless teaching}

Teacher A: During an observation, Teacher A deliberately and mindfully addressed specific writing elements (Dednam 2008:127). Teacher A achieved this by using previous test papers to practise writing skills required by the WCED. She used the examples to assist learners in developing their reading comprehension skills. She took the opportunity to assist them in writing the answers in full sentences using correct punctuation. It could be identified as an integrated writing lesson based on comprehension. As a whole class, including Grade 2's and 3's, each learner received a copy of the reading text entitled 'History of Mandela', which was three paragraphs long. They all read the passage together on the mat with the teacher. The teacher probed the learners' thinking by asking them questions about the passage. At first, she asked the learners questions that were obvious, 'What did the mom have to do?' Some questions the learners had to infer from the passage, 'Write the sentence that tells us that it was a hot day.' Other questions required learners to think beyond the passage and be critical, 'Do you think that the mom was happy that the sun was shining? Why?'

Learners returned to their desks to complete this written activity on the page provided. There were five different writing activities that the learners were required to complete. They included: spelling of words, dictionary skills, tenses, punctuation, and sentence construction. The learners had to find the correct spelling of words in the text. There were words that needed to be arranged in alphabetical order. Sentences needed to be changed from the past tense to the present tense. There were sentences that needed to be rewritten with correct punctuation. Finally, they had to write a paragraph to describe Mandela.
Although the teacher guided this process, she did not prescribe the actual written answers. Each learner was given the opportunity to read from the passage and the questions in order to write answers in full sentences on the board. She encouraged learners who found writing challenging to participate. By using this method of teaching, she was revising and extending vocabulary, spelling, punctuation, dictionary skills, and sentence construction.

Evidence shows that Teacher A was mindfully and explicitly attempting to improve her Grade 2 and 3 learners' reading and writing skills.

Teacher B: Teacher B introduced her lessons by mindfully and explicitly demonstrating writing skills she had identified as lacking in the previous day's work. She consciously provided an activity that consolidated necessary writing skills. For example, she demonstrated what a good sentence should consist of before learners wrote their news. Below is a detailed transcript of how Teacher B taught her learners to construct sentences using capital letters, full-stops, and adjectives. She made her learners aware of spacing between words:

TB: We are going to write our news today. Before we write it, can anyone provide me with an example of a good sentence?

L25: I played.

TB: What do I start my sentence with?

L16: A capital letter.

TB: (Writes the statement on the board) I played. What do I end my sentence with?

L36: A full stop.

TB: How can I improve my sentence? What can I add to my sentence that will tell me more about what I did?

L41: I played yesterday.

L6: I played on Sunday.

TB: Good, we say when I played. What did I play with? Who did I play with?

L12: Yesterday I played with my brothers.

L26: Yesterday my brothers and I played with the dog.

TB: Good, now we have when, who and what. What comes at the end of my sentence?

L15: A full stop.

TB: (Writes the sentence on the board). Well done, now when you write your news, I want you to tell me everything.

Don't forget finger spaces between your words. I want 2 paragraphs with 10 sentences altogether from the Grade 3 's and 1 paragraph with 5 sentences from the Grade 2's.

L22: Can we write more sentences if we want to?

TB: Yes, but read what you have written first 
In this excerpt, Teacher B demonstrated analytical writing skills (sentence construction, use of correct grammar, and editing skills) needed for her learners to be independent and to develop a culture of correct sentence structure. These skills are explained in the RNCS (South Africa, Department of Education 2002) and the Foundations for Learning and Assessment Framework policy document (South Africa, Department of Education 2008). They provide a detailed, clear line of progression in the development of sentence structure. Dednam (2008:127) believes essay writing is the most difficult form of writing. Cambourne (2004:35) argues that when the necessary writing behaviours are mindfully demonstrated to learners, they will have a better grounding for writing essays independently.

\section{Contextualised teaching versus de-contextualised teaching}

Teacher A: Teacher A presented a lesson in which she chose a poem about a street sweeper sweeping leaves on a windy day, and the learners needed to write the answers to the comprehension questions. Learners related to this; some of their parents were 'gardeners', 'labourers' as well as 'nannies' on nearby farms. They knew about windy days. Since her learners could easily relate to this topic, it could be deduced that this lesson was a contextually relevant lesson. They could relate to how frustrating it was to work when the wind was so strong. Two examples provided by learners were: attempting to hang up washing when the wind kept blowing it down repeatedly; and the frustration of trying to keep a cap on in the wind. During a later visit, when observing the written responses to the comprehension questions, it appeared that the learners had engaged with this text and answered many questions correctly.

During another observation, Teacher A read a passage for comprehension about a washing machine. After reading the story to the class she noticed that the learners were silent. She asked which learners had a washing machine. Nobody responded. Learners were not exposed to the use of washing machines. Teacher A continued by asking if any of the learners had seen a washing machine. Again nobody responded. She tried to explain that it was a machine that had a part inside that spun in order to wash the clothes. She told them that she would bring a picture to show them what a washing machine looked like. When she asked the learners how their parents did the washing, they answered: 'In the bath (ten responses) ... in a bucket (seventeen responses) ... in a basin (twelve responses) ...' These were the three most common answers and the learners were content with the information of their peers as they too shared the same experiences.

The researcher observed the teacher's facial expressions during this lesson and came to the conclusion that she was surprised that her learners had no prior knowledge of 'washing machines'. This indicated to the researcher that this teaching moment was not intentional, yet it led to the text being decontextualised. The final result of this lesson was that the teacher chose not to ask her learners to complete the comprehension passage as she could see that the content made no sense to them.

Teacher B: Teacher B asked her learners to pretend they were 'crayons'. They had to decide what colour they wanted to be and where they wanted to go. She asked them to describe what they would do by writing their responses in their exercise books.

The results of the learners' written work indicated that they understood the use of colours. The learners' interpretation of the concepts 'what' and 'where' was short, yet clear. For example, one learner wrote that she wanted to be a 'red crayon' in her teacher's pencil bag because she would feel safe there. Although it was a short sentence, it indicated that the learner felt safe with her teacher. It was clear 'what' she wanted to be and 'where' she wanted to go. This is a good example of Cambourne's (2004:35) contextual learning because 'it made sense to the learners. Because it makes sense it is not only less complicated, but it is also more likely to result in robust, transferable, useful, and mindful learning.'

\section{Discussion}

The goal of this paper was to use Cambourne's social constructivist theory of instructional principles to comprehend the complexity of the teaching of writing in two rural multigrade classes. Although the South African Manifesto on Values, Education and Democracy (South Africa, Department of Education 2001a) aimed to promote social justice, equity and equality, this research project found that rural multigrade learners can receive quality education but that this depends on the teachers.

Cambourne and many literacy experts (Dednam 2008; Hamston \& Resnick 2009; Johnston 2010) agree that writing is a multifaceted subject, but suggest that using the four instructional principles, congruent with constructivism, may be a useful framework for understanding teaching and learning in a writing classroom. There is evidence, both from theory and practice that some aspects of Cambourne's instructional principles did emerge in both teachers' writing classrooms, to varying degrees along the teaching and learning continuum.

Although Teacher A was a more experienced teacher, based on the few lessons observed, she created an environment in which her Grade 2 and 3 learners were not encouraged to construct knowledge from others (Cambourne 2004) but were encouraged to write independently with little support. There were many examples of where she did not know how to engage with learners and support them with their writing skills. This uncertainty restricted their level of engagement with their writing tasks. Although Teacher A demonstrated some lessons, which included some writing skills and strategies, these lessons were mostly taught implicitly (Cambourne 2004). Teacher A deliberately and mindfully practised the writing skills (Dednam 2008) required by the 
WCED by using previous tests and examination papers. However, there were many examples where she had not systematically planned her writing lessons; too much time was wasted. It appeared that Teacher A was not aware of the need to provide authentic, contextually relevant texts to her learners.

On the other hand, Teacher B provided integrative writing lessons, where the learners in her class were co-constructors of their own knowledge in an environment that was similar to where they would apply that knowledge (Cambourne 2004). She created an environment in which social negotiations of meaning were encouraged as a significant part of her learning culture. The sharing of writing experiences amongst her Grade 2 and 3 learners, and discussions about the processes and understandings of how to improve their writing skills was promoted. Learners were encouraged to think critically and examine their own understanding at a metacognitive level.

\section{Conclusion}

There is international growing evidence that well-supported multigrade schools can provide positive educational outcomes. India is an example of innovative multigrade teaching methodology that is cost-effective and highly successful, both in rural and urban primary schools (Padmanabha Rao \& Rama 2010). Therefore, multigrade environments are not the real issue. As in this study, the issue was the teachers' understanding of Cambourne's theory of social constructivism and how it impacted on Foundation Phase learners' writing practices in multigrade classes. Both teachers created an environment that was conducive to effective learning. However, Teacher B, using Cambourne's four instructional principles, created a more constructivist classroom environment for developing writing skills for both her Grade 2 and 3 learners. Both teachers attempted to develop independent writing skills with their learners (Vygotsky 1986).

Because both these schools were in rural areas where the parents were illiterate, attempting writing skills was a difficult task for both teachers. Together with the curriculum, resources proved to be a challenge for both teachers. The lack of basic resources such as books, stationery, learning materials, warm clothes, and food hampered both teachers' ability to teach writing, and for the learners to learn effectively. Having the right resources is important and influences the quality of teaching and learning (Hoadley \& Jansen 2010:105).

This study was limited to researching only writing skills in two rural multigrade (Grade 2 and 3 classes) Foundation Phase classrooms. At all times, the researcher was mindful of the close link between reading and writing. The learners in these classes were between the ages of seven and 10 years old. It was believed that even though this study is limited to these grade groups, it does not make the study less significant.
A recommendation is that teacher-training institutions and in-service workshops should provide modules on teaching in rural multigrade environments. In these modules, discussions on how poverty and illiteracy may impact on the development of writing skills need to be included. Strategies should be offered on how teachers can use the more advanced learners, not necessarily the older learners, in the class to assist the slower learners. A final recommendation is that these two rural multigrade teachers would like more professional development on writing skills provided by knowledgeable others in NGO's and the WCED.

\section{Acknowledgements Competing interests}

The authors declare that they have no financial or personal relationships which may have inappropriately influenced them in writing this article.

\section{Authors' contributions}

Both B.B. (Cape Peninsula University of Technology) and J.C. (Cape Peninsula University of Technology) contributed equally to the writing of this article.

\section{References}

Beukes, F.C.G., 2006, 'Managing the effects of multigrade teaching on learner performance in Namibia', unpublished M.Ed. thesis, University of Johannesburg, Johannesburg

Blease, B., 2014, 'Exploring writing practices in two foundation phase rural multigrade schools', unpublished M.Ed. thesis, Cape Peninsula University of Technology, Cape Town.

Bloch, G., 2009, The toxic mix: What is wrong with South Africa's schools and how to fix it?, Tafelberg, Cape Town.

Brunswic, E. \& Valerien, J., 2004, Multi-grade schools: Improving access in rural Africa?, viewed n.d., from http://www.unesco.org/iiep

Cambourne, B., 2000, 'Conditions for literacy learning: Turning learning theory into classroom instruction: A mini-case study', The Reading Teacher 54(4), 414-417.

Cambourne, B., 2004, 'Holistic, integrated approaches to reading and language arts instruction: The constructivist framework of an instructional theory', in A.E. Farstrup \& S.J. Samuels (eds.), What research has to say about reading instruction, 3rd edn., pp. 25-47, The International Reading Association, Newark.

Chetty, R., 2010, 'Politics and policies of multigrade education in South Africa', paper presented at the Southern African Conference for Multigrade Education, Paarl, South Africa, March 2010, pp. 22-24.

Creswell, J.W., 2012, Educational research: Planning, conducting, and evaluating quantitative and qualitative research, 4 th edn., Pearson, Boston.

Czerniewicz, L. \& Brown, C., 2014, 'The habitus and technological practices of rural students: A case study', South African Journal of Education 34(1).

Davis, A. \& McGrail, E., 2009, "'Proof-revising" with podcasting: Keeping readers in mind as students listen to and rethink their writing', The Reading Teacher 62(6), 522-529. http://dx.doi.org/10.1598/RT.62.6.6

Dednam, A., 2008, 'First language problems', in E. Landsberg, D. Kruger \& N. Nel (eds.), Addressing barriers to learning: A South African perspective, pp. 119-144, Van Schaik, Pretoria.

Estyn, R., 2011, An evaluation of the implementation of the Foundation Phase for five to six-year-olds in primary schools, with special reference to literacy, September 2011, Cardiff, South Wales.

Hamston, S. \& Resnick, L.B., 2009, Reading and writing with understanding, The New Standards, Washington.

Henning, E., Van Rensburg, W. \& Smit, B., 2007, Finding your way in qualitative research, Van Schaik, Pretoria.

Hlalele, D., 2012, 'Exploring rural high school learners' experience of mathematics anxiety in academic settings', South African Journal of Education 32(3), 267-278.

Hoadley, U. \& Jansen, J., 2010, Curriculum: Organizing knowledge for the classroom, 2nd edn., Oxford University Press, Cape Town.

Hsu, C., 2009, 'Writing partners', The Reading Teacher 63(2), 153-158. http://dx.doi. org/10.1598/RT.63.2.6

Johnston, P., 2010, Standards for the assessment of reading and writing, International Reading Association, Newark. 
Joubert, J., 2010, 'Multigrade schools in South Africa: Overview of a baseline study conducted in 2009 by the Centre for Multigrade Education, Cape Peninsula
University of Technology', paper presented at the Southern African Conference University of Technology', paper presented at the Southern Afric
for Multigrade Education, Paarl, South Africa, March 22-24, 2010.

Little, W.A., 2005, 'Learning and teaching in multigrade settings', paper prepared for the UNESCO 2005 EFA Monitoring Report, London.

Little, W.A., 2007, 'Education for all: Multigrade realities and histories', in A.W. Little (ed.), Education for all and multigrade teaching: Challenges and opportunities, pp. 1-26, Springer, Houten.

McMillan, J.H. \& Schumacher, S., 2006, Research in education: Evidence-based inquiry, 6 th edn., Pearson, New York.

NEEDU Report, 2013, National report 2012: The state of literacy teaching and learning in the Foundation Phase, April 2013.

Padmanabha Rao, Y.A. \& Rama, A., 2010, 'Redesigning the elementary school multilevel perspectives from River Rishi Valley Institute for Educational Resources', paper presented at the Southern African Conference for Multigrade Education, paper presented at the Southern African
Paarl, South Africa, March 22-24, 2010.

Potgieter, M., 2010, 'Ons Vergete Skole', Die Burger, 4 February, p. 4.

Pretorius, E.J. \& Mampuru, D.M., 2007, 'Playing football without a ball: Language, reading and academic performance in a high-poverty school', Journal of Readin Research 30(1), 38-58. http://dx.doi.org/10.1111/j.1467-9817.2006.00333.x

Prinsloo, E., 2005, 'Socio-economic barriers to learning in contemporary society', in E. Landsberg (ed.), Addressing barriers to learning: A South African perspective, pp. 27-41, Van Schaik, Pretoria.
Scott, J.L., Teale, W.H., Carry, D., Johnson, N. \& Morgan, D., 2009, 'Effective literacy instruction for urban children: Voices from the classroom', The Reading Teacher 63(4), 338-341. http://dx.doi.org/10.1598/RT.63.4.11

South Africa, Department of Education, 2001a, Manifesto on values, education and democracy, Government Printers, Pretoria.

South Africa, Department of Education, 2001b, Education white paper 6: Special needs education: building an inclusive education and training system, Government Printer, Pretoria.

South Africa, Department of Education, 2002, Revised national curriculum statement. Grade $R$ to 9 . Policy document, Government Printer, Pretoria.

South Africa, Department of Education, 2008, Foundations for learning and assessment framework, Government Printers, Pretoria.

Taylor, N., 2008, 'What's wrong with our schools and how can we fix them?', paper presented at the CSR in Education Conference, TSiBA Education, Cape Town, 21 November.

UNESCO, 2004, The plurality of literacy and its implications for policies and programs. UNESCO education sector position paper 13, UNESCO, Paris.

Vygotsky, L.S., 1986, Thought and language, MIT Press, Cambridge.

Wiersma, W. \& Jurs, S.G., 2005, Research methods in education, 8th edn., Pearson, New York.

Woolfolk, A., Hughes, M. \& Walkup, V., 2008, Psychology in education, Pearson, London. 